\title{
Thermostimulated luminescence of plasma electrolytic oxidation coatings on 6082 aluminium surface
}

\author{
Aleksejs Zolotarjovs*, Krisjanis Smits, Katrina Laganovska, Ivita Bite, Larisa Grigorjeva, \\ Krisjanis Auzins, Donats Millers, Linards Skuja \\ Institute of Solid State Physics, University of Latvia, Latvia
}

\section{A R T I C L E I N F O}

\section{Keywords:}

Plasma electrolytic oxidation

PEO

Dosimetry

TSL

Alumina

Luminescent coating

\begin{abstract}
A B S T R A C T
For decades, plasma electrolytic oxidation (PEO) coatings are actively studied and applied to protect the surface of various valve metals from chemical or mechanical damage. However, over the last couple of years intense research is being done to explore additional possibilities of the PEO coatings apart from their classical application. One of the possible additional uses is thermostimulated luminescence dosimetry that is already widely applied for environmental and health monitoring. This research proposes a method to produce a novel functional coating on aluminium surface exhibiting intense thermostimulated luminescence signal that could be used for dosimetry of ionizing radiation. The result was achieved using plasma electrolytic oxidation with modified electrolyte to introduce carbon ions into the oxide thus inducing defects in the crystalline structure of the coating. Al6082 aluminium alloy was used as a substrate, $\mathrm{KOH}$ and ethanol mixture as an electrolyte. A bipolar pulsed regime was used for $15 \mathrm{~min}$. The obtained coating combines the desired luminescence properties with a good mechanical stability due to the relatively hard cubic phase of the coating. Scalability of the technology and low production cost makes the coatings prospective for various practical applications.
\end{abstract}

\section{Introduction}

Plasma electrolytic oxidation (PEO) is an electrochemical process used to obtain thick (Snizhko et al., 2004) oxide coatings on various valve metals. Although this technology was developed more than 40 years ago (Yerokhin et al., 1999) (Yerokhin et al., 1998) it is still under development and research because of its scientific and commercial value. As the main use of the coatings is to protect metal from the environment, an extensive research is done to improve their mechanical (White et al., 2016) and chemical properties (Liang et al., 2009) or even to produce thermal barriers (Curran et al., 2007).

One of the trends of PEO studies is quickly gaining traction: the addition of the luminescence properties to PEO coatings. Various studies were performed to obtain luminescent coatings on aluminium (Smits et al., 2015), zirconia (Stojadinović et al., 2016) or zinc (Grigorjeva et al., 2015) with the most significant difference between them being the method of coating modification to introduce rare earth (RE) ions or other atoms into the structure of coatings. A large number of variable parameters (Kalkanci and Kurnaz, 2008) (electrolyte, electrodes, various electrical parameters, material used, electrolyte temperature etc.) allow for many ways to implement the doping of the coating. The most straight forward approach uses an already doped material (alloy) (Smits et al., 2015); however, due to the cost of REdoped metal and the lack of optimisation this approach is useable only for scientific interest. Another approach is to use the recently developed pore filling method (Zolotarjovs et al., 2016), but despite the great versatility of this method it is not practical for commercial use due to the multi-step nature of the process. Finally, using modified electrolyte (adding some concentration of dopants to the electrolyte mixture) proved to be the most commercially viable and effective approach (Stojadinović et al., 2016); however, there are no results with real commercial value yet.

The main aim of this research is to evaluate the possibility of using PEO coatings for dosimetric applications based on thermostimulated luminescence. Fig. 1 demonstrates the proposed concept of the application. To solve the problem of making a good dosimeter using the PEO method, one can look for inspiration at the already existing dosimeters. One of the most popular commercially available dosimeters is "TLD500" - alumina doped with carbon. Since the first research of this material as a TSL dosimeter done in 1990 by Akselrod et al. (Akselrod MKortov and Kravetsky, 1990), it was evident that such a material can perform well as a personal TSL dosimeter because it has an intense,

\footnotetext{
* Corresponding author.

E-mail address: aleksejs.zol@gmail.com (A. Zolotarjovs).
} 


\section{PEO Oxidation}

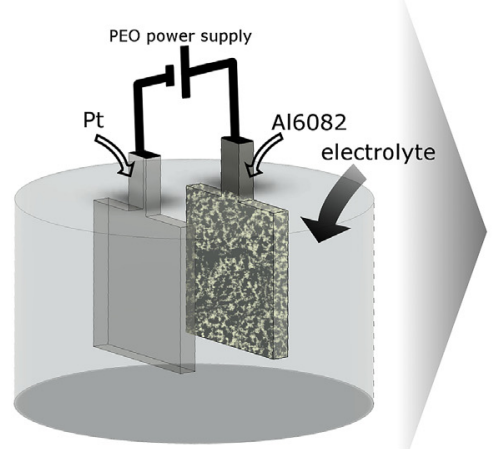

Irradiation

\section{Readout}

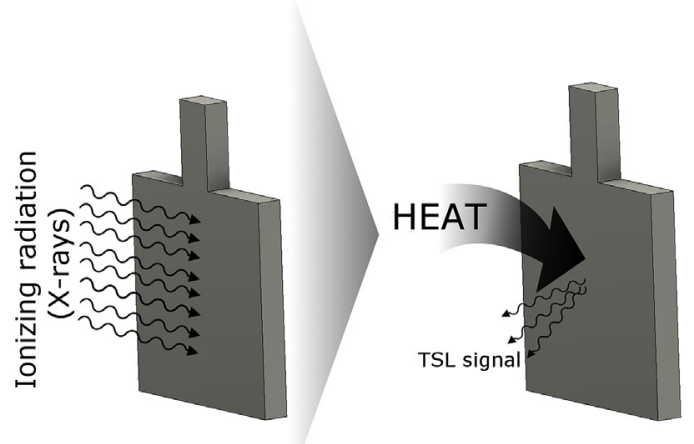

Fig. 1. Proposed principle of PEO coating-based dosimeter.

narrow TSL peak (Yang et al., 2008), the intensity of which is proportional to the absorbed dose in a wide range $\left(10^{-6} \mathrm{~Gy}-1 \mathrm{~Gy}\right.$ gamma-dose $)$ (Akselrod MKortov and Kravetsky, 1990). An additional advantage, this material can be produced by many different methods (Yong et al., 2013). On top of that, recent studies demonstrate the possibilities and advantages of optically stimulated luminescence dosimetry on TLD-500 (Tanir et al., 2012) (Meriç et al., 2015) (Akselrod et al., 2006).

The PEO process was developed mostly to improve the mechanical properties of the coating therefore there is an abundance of studies where various crystalline phases of alumina were obtained, including the hardest alumina phase ( $\alpha$, corundum) (Khan et al., 2010) (Dehnavi et al., 2014). However, the TSL signal from an unmodified PEO coating in alpha - or any other phase is negligible and cannot be directly used for dosimetry. Therefore, the main problem to overcome is the doping of alumina coating with carbon. As discussed previously, the most commercially viable method is by using modified electrolyte, thus a highly soluble substance should be used as a source of carbon.

To keep the research as close to practical applications as possible, only commercially viable materials and methods were used in the present study: doping through electrolyte, refraining from the use of rare earth ions, and selecting one of the most popular aluminium alloys (Al6082) as the substrate.

\section{Experimental details}

\subsection{Samples}

The substrate material (Al6082) consists of 95-98\% aluminium with the addition of $\mathrm{Cr}, \mathrm{Cu}, \mathrm{Fe}, \mathrm{Mg}, \mathrm{Mn}, \mathrm{Si}, \mathrm{Ti}, \mathrm{Zn}$ and other metals with concentrations varying from $0.1 \%$ to $1.3 \%$. In this study, a $3 \mathrm{~mm}$ thick aluminium sheet was cut into samples of size $25 \times 25 \times 3 \mathrm{~mm}^{3}$, each having the total surface area of $15.5 \mathrm{~cm}^{2}$. All samples were rinsed in acetone and ethanol and dried before the PEO process.

\subsection{PEO setup}

Custom $5 \mathrm{~kW}$ bipolar pulse electric generator ELGOO PEO V3 was used. The device is externally controlled via PC which allows great repeatability and high customization of parameters including pulse timing, voltage, current and their change in time. In this study, samples were prepared using roughly estimated initial parameters and then optimized for best TSL intensity. Only the best sample is presented in this paper.

The electrolyte consisted of 3 components: deionized water, $2 \mathrm{~g} / \mathrm{L}$ $\mathrm{KOH}$ and $60 \mathrm{ml} / \mathrm{L}$ ethanol. The additive we chose for this study is ethanol due to its high solubility; however, other carbon - containing chemicals could be used as well. Electrolyte was contained in double walled water-cooled reaction chamber thus a stable $20 \pm 5{ }^{\circ} \mathrm{C}$ temperature was maintained.
Square voltage-limited non-symmetrical $5 \mathrm{~ms}$ pulses were used with the voltages of $+700 \mathrm{~V}$ and $-233 \mathrm{~V}$. 1 ms pauses were set in-between pulses. The AC regime with the $1 / 3$ ratio of positive and negative pulses was chosen to reduce porosity (Xin et al., 2006). Current density remained constant with minimal decline over the course of $15 \mathrm{~min}$ and was equal to $0.6 \mathrm{kA} \mathrm{m}^{-2}$. Pt plate was used as a counter electrode. Processing time was set to $15 \mathrm{~min}$. The limit on the processing time was chosen based on the optimisation procedure with the luminescence intensity as the main parameter. The observed decrease of the TSL intensity after $15 \mathrm{~min}$ is mainly due to the degradation of the electrolyte evaporation of the ethanol as well as local increase in temperature causing the irreversible effects with slight colour change to yellow.

\subsection{Measurements}

TSL luminescence measurements were performed on a custom TSL setup consisting of: heating element (heating speed $-12 \mathrm{~K} / \mathrm{s}$, range: $293 \mathrm{~K}-700 \mathrm{~K}$ ), vacuum chamber (Ilmvac turbomolecular pump providing vacuum higher than $10^{-5}$ Torr), $\mathrm{X}$-ray tube with $\mathrm{W}$ anode operating at $30 \mathrm{kV}, 10 \mathrm{~mA}$ and detection system with 2 separate modules first one Andor DU-401 A-BV IDus CCD camera coupled with Andor Shamrock B-303i spectrograph and the second one - Hamamatsu PMT attached directly to the chamber. Dual registration system allows registering the whole spectral distribution of TSL with CCD as well as registering low intensity integral signals with PMT. Spectra measured with CCD were not corrected to accommodate differences in detection at different wavelengths as only the comparison study was performed. Slight differences between XRL and TSL spectral distribution in the PEO sample are partly caused by the different monochromator slit widths $50 \mu \mathrm{m}$ in case of XRL (spectral resolution $1 \mathrm{~nm}$ ) and $2000 \mu \mathrm{m}$ during TSL measurement (spectral resolution of $15 \mathrm{~nm}$ ).

The X-ray diffraction (XRD) spectrometer PANalytical X'Pert Pro was used to determine crystalline structures. Scanning electron microscopy (SEM) was performed on Phenom PRO desktop SEM.

Consumer-grade CMOS camera (Canon EOS 1100D) with 35s exposure time was used for evaluation of practical application of PEO coating (see Fig. 6). A uniform heater BIOSAN MSH 300 with a surface temperature of $300 \mathrm{C}$ was used to heat the samples during the measurement.

The element analysis of coating was performed using transmission electron microscope (TEM, Tecnai G2 F20, FEI) operated at $200 \mathrm{kV}$. The powder-like TEM samples were prepared by mechanical scraping from coating using diamond cutter and placed on Lacy carbon film grid AGS166 (Agar Scientific). 


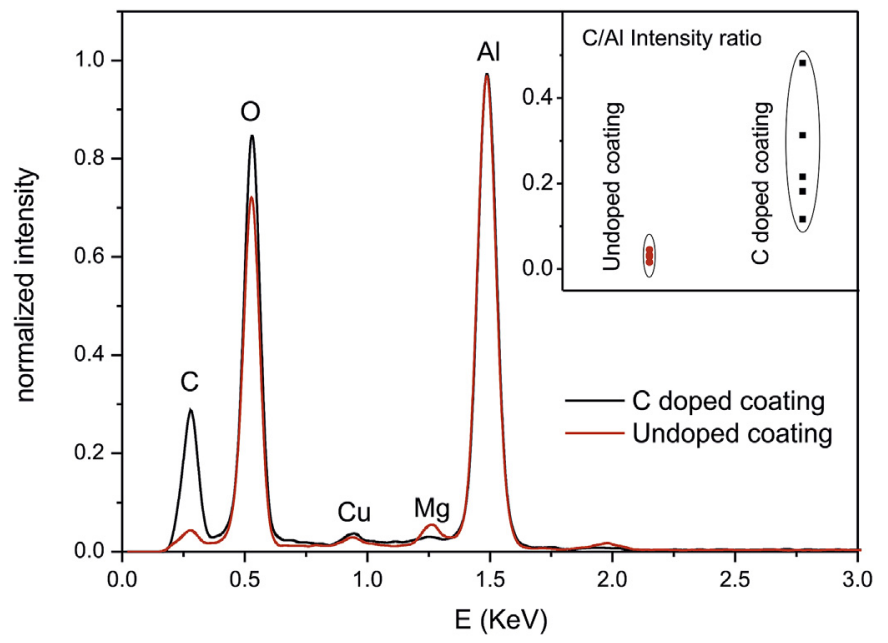

Fig. 2. TEM EDX measurements of obtained coatings. Insert shows the $\mathrm{C} / \mathrm{Al}$ line intensity ratio for five different particles of both samples.

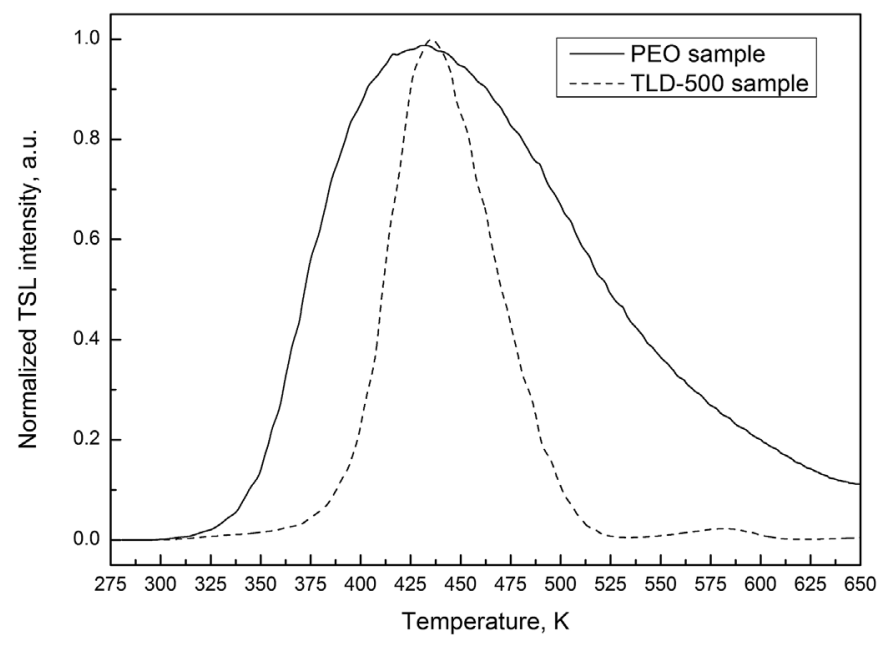

Fig. 3. TSL glow curves of C-doped PEO and TLD-500 Al2O3:C dosimeter samples.

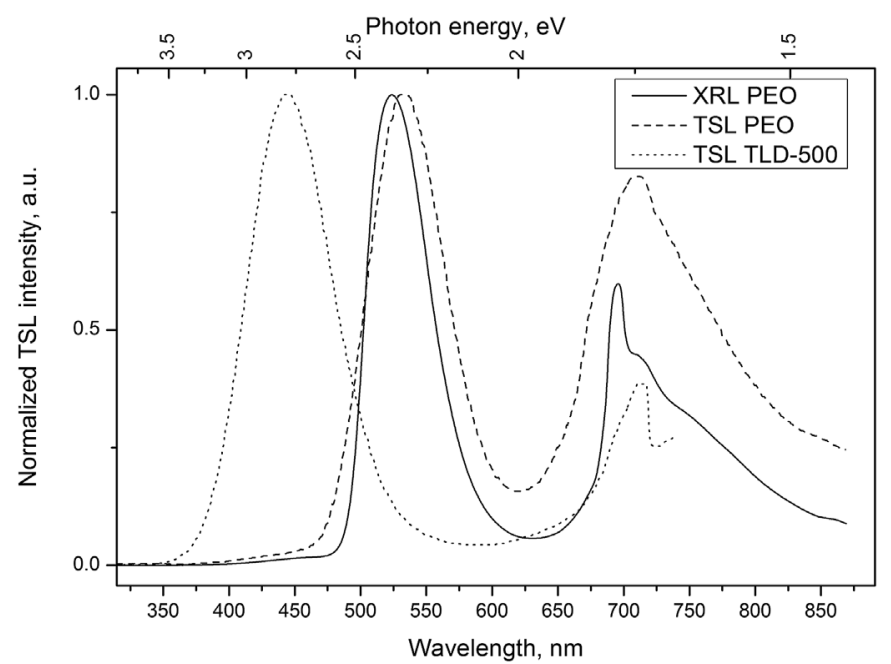

Fig. 4. Spectral distribution of XRL and TSL of the PEO sample as well as the TLD-500 sample for reference.

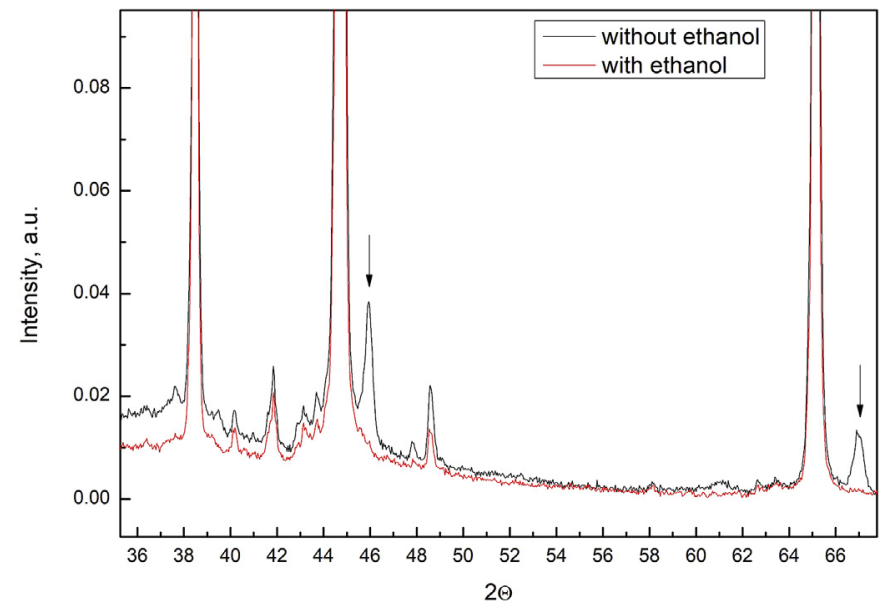

Fig. 5. XRD graph of PEO coating prepared with ethanol in electrolyte as well as PEO coating without ethanol for a comparison. Arrows mark the position of eta- or gamma- phase peaks. The off-scale peaks are due Al substrate.

\section{Results and discussion}

\subsection{Coating characterisation}

As it was mentioned previously, undoped alumina PEO coating does not exhibit TSL signal, therefore the first task is to incorporate carbon in the structure. Several approaches were evaluated as the pilot experiments for this study; however, the best result was obtained by the modification of the electrolyte with highly soluble organic substance ethanol. To verify the implementation of the carbon ions in the coating the TEM EDX measurements were performed (Fig. 2). By analysing and comparing the intensity of $\mathrm{K} \alpha$ line of carbon at $0.277 \mathrm{KeV}$ it is evident that the carbon atoms are indeed incorporated in the structure. The wide variations of carbon concentration in doped coatings (Fig. 2, inset) are ascribed with non-uniform distribution of carbon ions in the coating. Even though electron beam for EDX measurements was focused in small areas without any Lacey film underneath the particle, undoped samples still show a small carbon signal, which originates from electron multiple scattering, similarly to the $\mathrm{Cu}$ signal from $\mathrm{Cu}$ grid.

The knowledge about electronic processes in the sample related to visible luminescence output is crucial for analysis of any possible dosimeter, therefore multiple TSL measurements were performed for both the reference sample (TLD-500) and the obtained C-doped PEO coating (Fig. 3). The PEO coating exhibits a broad TSL peak extending from $300 \mathrm{~K}$ up to $630 \mathrm{~K}$ (full width at half maximum, FWHM $=150 \mathrm{~K}$ ). Its width indicates a very broad trap distribution in the lattice, covering a wide energy range. To compare the coating with the existing technology, TSL of TLD-500 was measured and the obtained TSL glow curve and spectral distribution coincide well with the literature (Kalita and Chithambo, 2017a) (Palan et al., 2016) (a Weinstein et al., 2002) - with a characteristic luminescence band at $400 \mathrm{~nm}$ and a TSL peak at $440 \mathrm{~K}$ associated with $\mathrm{F}$ and $\mathrm{F}^{+}$centres. When comparing both samples (PEO coating and TLD-500) one can see that although the general positions of the TSL maxima are similar, their FWHMs are drastically different. The width of the TSL peak is directly correlated with the energy distribution of a trap - the smaller the FWHM, the more defined activation energy is. Since the carbon-doped PEO coating exhibits extremely broad TSL peak, one can conclude that the possibilities of a localized electron to recombine are broad which is due to irregularity of the atomic structure present in the coating. The difference between highly ordered crystalline structure of TLD-500 and mostly amorphous structure of the coating is evident.

The difference of FWHM of the PEO sample and TLD-500 should be studied in finer details to better understand the nature of the traps 

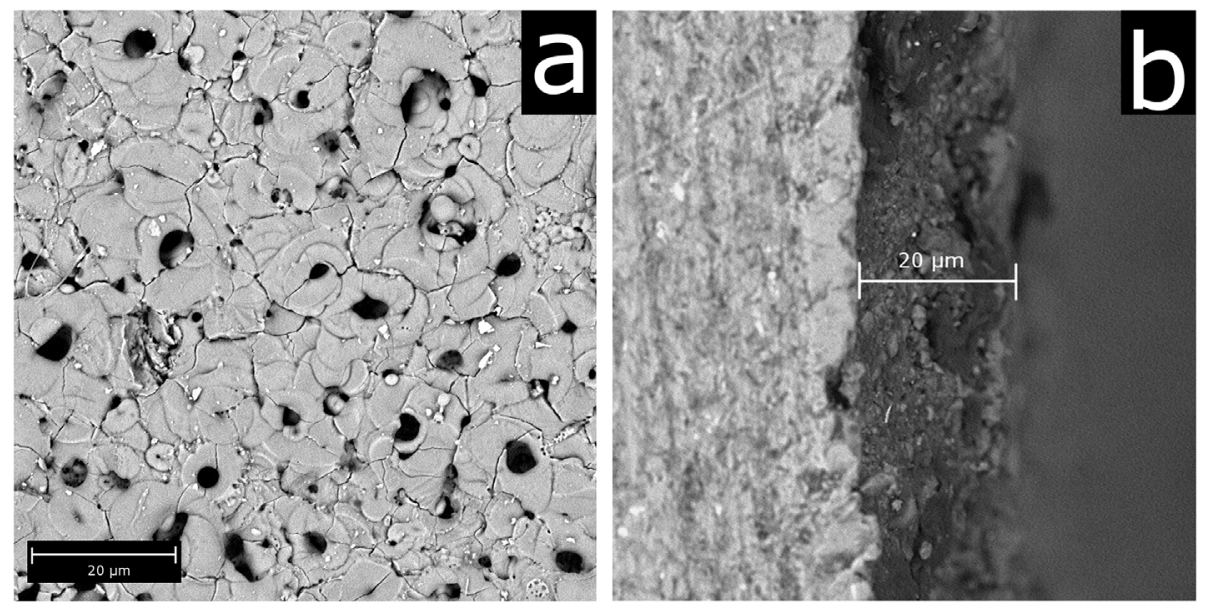

Fig. 6. SEM image of coating (a) as well as cross section of coating showing the thickness of $20 \mu \mathrm{m}$ (b).

which was done by measuring the spectral distribution of TSL signal from the samples. Fig. 4 shows the spectral distribution for the TSL maximum at $440 \mathrm{~K}$ for both the PEO coating and the TLD-500 samples as well as the X-ray induced luminescence (XRL) spectrum measured from PEO sample under irradiation. (Fig. 4). Although trap centres in the PEO coating and TLD-500 crystal are similar, the luminescence main peak position varies drastically. The luminescence maximum at $420 \mathrm{~nm}$ of TLD-500 was studied in depth by Akselrod et al. and is described as the $\mathrm{F}^{+}$centre charge compensated by $\mathrm{C}^{2+}$ ions in the $\alpha$ $\mathrm{Al}_{2} \mathrm{O}_{3}$ matrix (Akselrod et al., 1990). However, this is not the case for the PEO coating - luminescence is shifted to the green region to $530 \mathrm{~nm}$. Similar case was observed by Rodriguez et al. for $\mathrm{Al}_{2} \mathrm{O}_{3}$ doped with $\mathrm{Mg}$ and $\mathrm{C}$ (Rodriguez et al., 2011). Here, $\mathrm{F}_{2}{ }^{2+}(2 \mathrm{Mg})$ centre is a result of charge compensation for the substitutional $\mathrm{Mg}^{2+}$ ion in $\mathrm{Al}^{3+}$ site. $\mathrm{Mg}$ ion is present in the substrate (aluminium alloy) as well as its presence in the coating is confirmed by the TEM EDX measurements (Fig. 2).

The PEO coating exhibits also the complex red band - a combination of various metal oxide luminescence bands. As the starting alloy (Al6082) contains many additives to improve its mechanical properties, they are expected to incorporate in the obtained coating too. TEM EDX results confirm the presence of other (apart from $\mathrm{Al}$ ) metal ions, like $\mathrm{Mg}$ that are implemented in the coating from the substrate metal.

As an example, Mg (Kalita and Chithambo, 2017b), Mn (MartínezMartínez et al., 2005) or Cr (Salek et al., 2016) oxides exhibit luminescence in the red region of the spectrum; however, due to the amount of co-dopants in the coating it is hard to distinguish any particular lines apart from the most intense $\mathrm{Cr}^{3+}$ R-line doublet at 693-694 nm.

The assumption of the irregular structure in the coating is based on the relatively short PEO time ( $15 \mathrm{~min}$ are usually not enough for the formation of corundum) as well as on the FWHM of TSL. To address this assumption, the XRD spectra of coatings obtained with and without ethanol in electrolyte (all other parameters were kept unchanged) were compared (Fig. 5). One can see that apart from the main aluminium peaks at 38.44, 44.69 and $65.07 \mathrm{deg}$. (from the substrate), several others are present in the diffraction pattern of the coatings. The small peaks visible in $39-44^{\circ}$ region (as well as peak at $48.7^{\circ}$ ) originate from the different phases present in the alloy itself (Al6082), e.g. Mg2Si phase and various intermetallic phases. After comparing data to the XRD database (Graulis et al., 2009), it was concluded that peaks at 45.87 and $66.86 \mathrm{deg}$. are due to the presence of eta- or gamma- phase in the alumina coating and correspond well with the JCPDS cards \#29-0063 and \#50-0741 (marked with arrows on Fig. 5). Some additional crystalline structure is present in the sample without ethanol and the addition of ethanol in electrolyte prevents the crystalline phase from occurring due to the increased defect concentration from incorporation of $\mathrm{C}$ atoms.

Although many studies reported the possibility to obtain alphaphase aluminium oxide with PEO using longer processing time (Yerokhin et al., 2003) (Tian et al., 2002), the optimisation of the parameters in this study revealed the loss of TSL intensity with increased PEO time, therefore this approach does not allow synthesis of trigonal alumina dosimetry coating. Additional studies on optimizing the electrolyte composition, temperature and time are needed to obtain $\alpha$-phase alumina by PEO.

The thickness and morphology of the "ethanol-processed" coating were studied using SEM. (Fig. 6). It is evident that it looks like classical (undoped) PEO coating with a thickness of about $20 \mu \mathrm{m}$. Although some porosity is present, it is characteristic for PEO and can be used to an advantage (Curran and Clyne, 2006). The presence of ethanol in electrolyte does not seem to affect the coating morphology.

\subsection{Practical application evaluation - delayed radiation mapping}

By analysing the output intensity of the best PEO sample a conclusion can be drawn that coatings of this type exhibit easily measurable intense TSL signal in the visible light region. The possibility to use coatings as radiation detecting screens is demonstrated (Fig. 7). The concept is to apply the PEO coating to a large flat surface (e.g. aluminium sheet) and use it to get the distribution of ionizing radiation in experimental/medical/industrial setups. Due to the limitations of the power supply used in this study, the maximum surface area of the samples is limited to $15.5 \mathrm{~cm}^{2}$. To overcome this limitation, 4 identical samples were prepared and arranged in a grid ( 2 by 2 samples) giving the total active area of $25 \mathrm{~cm}^{2}$ (one side of the whole $2 \times 2$ arrangement). The grid was then irradiated with X-rays for $30 \mathrm{~min}$ (W anode, $30 \mathrm{kV} 10 \mathrm{~mA}$ ) from $10 \mathrm{~cm}$ distance. After the irradiation, the grid was placed on a pre-heated uniformly hot surface $(\mathrm{T}=300 \mathrm{C})$ and the luminescence from the grid was measured using a CMOS sensor in a commercially available camera with a long exposure (35s). Fig. 7 shows the obtained colour-corrected image.

In addition, by analysing a colour version of the image one can see that in the irradiated part of the grid tiles have a non-uniform colour distribution of the luminescence with the edges of the tiles emitting orange-red light and middle parts emitting green luminescence. The luminescence at the edges corresponds to the red band previously connected with ions of various metal additives in alumina coating, while the middle part of the tiles is dominated by the intrinsic luminescence of alumina. The difference between the luminescence output at the edges and in the middle is explained by the increased current density in the regions close to the sharp edges of the tiles. 


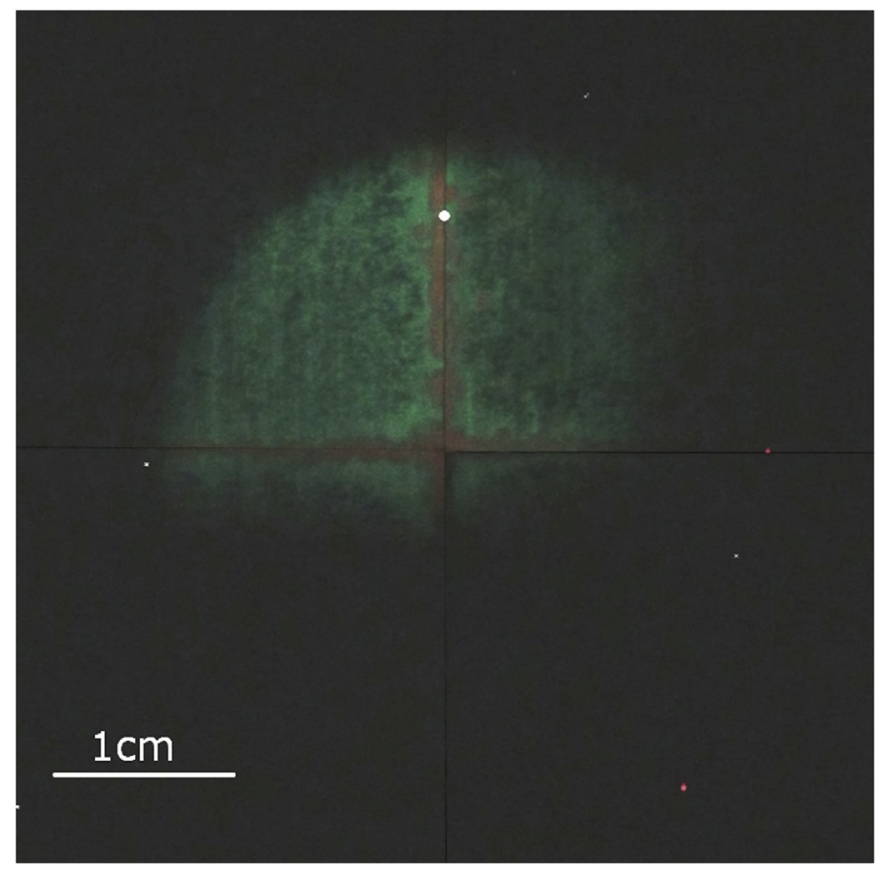

Fig. 7. TSL integral output image of X-ray irradiated C-doped PEO coating, taken by camera with CMOS sensor.

\section{Conclusions}

A new functional material was developed combining advantages of PEO alumina coatings (high mechanical and chemical stability, strong adhesion, ease of production) with an intense TSL signal, partly similar to the TSL of alumina-based dosimeters. Commercially viable approach was used: coating was made on a widely used aluminium alloy Al6082 and $\mathrm{KOH}+$ ethanol electrolyte to introduce carbon atoms in the structure. The TSL measurements revealed a very broad electron trap distribution in the electronic structure of the coating.

Glow curves and spectral distribution measured from the coating were compared to the closest commercially available dosimeter (TLD$500, \alpha-\mathrm{Al}_{2} \mathrm{O}_{3}: \mathrm{C}$ ) concluding that although some similarities are present (main TSL peak position), differences prevent the developed material to be used as a dosimeter in its current form. However, the functional coatings are proven to be useful for other practical applications e.g. as radiation detecting $2 \mathrm{D}$ screens.

Further studies should focus on actual dosimetry applications of the coating as well as explore new ways to modify coating structure to obtain higher luminescence output while preserving its outstanding mechanical properties.

\section{Acknowledgements}

Financial support provided by Scientific Research Project for Students and Young Researchers Nr. SJZ/2016/12 realized at the Institute of Solid State Physics, University of Latvia is greatly acknowledged.

Authors are grateful to R. Ignatans for measurements and analysis of XRD spectra and ElGoo Tech ltd. For providing PEO equipment.

\section{References}

a Weinstein, I., Pelenyov, V.E., Kortov, V.S., 2002. The effect of thermally stimulated photoconversion of oxygen centres on the sensitivity of TLD-500 dosimetric crystals. Radiat. Protect. Dosim. 100, 159-162. http://www.ncbi.nlm.nih.gov/pubmed/ 12382851.

Akselrod, M., Kortov, V., Kravetsky, D., Gotlib, V., 1990. Highly sensitive thermoluminescent anion-defective alpha-Al203: C single crystal detectors. Radiat. Protect. Dosim. 32, 15-20. https://doi.org/10.1093/oxfordjournals.rpd.a080715.
Akselrod, M.S., Botter-Jensen, L., McKeever, S.W.S., 2006. Optically stimulated luminescence and its use in medical dosimetry. Radiat. Meas. 41, S78-S99. https://doi. org/10.1016/j.radmeas.2007.01.004.

Akselrod M, G.V., Kortov, V., Kravetsky, D., 1990. Highly sensitive thermoluminescent anion-defective alpha-Al203:C single crystal detectors. Radiat. Protect. Dosim. https://doi.org/10.1093/oxfordjournals.rpd.a080715.

Curran, J.A., Clyne, T.W., 2006. Porosity in plasma electrolytic oxide coatings. Acta Mater. 54, 1985-1993. https://doi.org/10.1016/j.actamat.2005.12.029.

Curran, J.A., Kalkanci, H., Magurova, Y., Clyne, T.W., 2007. Mullite-rich plasma electrolytic oxide coatings for thermal barrier applications. Surf. Coating. Technol. 201, 8683-8687. https://doi.org/10.1016/j.surfcoat.2006.06.050.

Dehnavi, V., Liu, X.Y., Luan, B.L., Shoesmith, D.W., Rohani, S., 2014. Phase transformation in plasma electrolytic oxidation coatings on 6061 aluminum alloy. Surf. Coating. Technol. 251, 106-114. https://doi.org/10.1016/j.surfcoat.2014.04.010.

Graulis, S., Chateigner, D., Downs, R.T., Yokochi, A.F.T., Quirós, M., Lutterotti, L., Manakova, E., Butkus, J., Moeck, P., Le Bail, A., 2009. Crystallography Open Database - an open-access collection of crystal structures. J. Appl. Crystallogr. 42, 726-729. https://doi.org/10.1107/S0021889809016690.

Grigorjeva, L., Millers, D., Smits, K., Zolotarjovs, A., 2015. Gas sensitive luminescence of $\mathrm{ZnO}$ coatings obtained by plazma electrolytic oxidation. Sensor Actuator Phys. 234, 290-293. https://doi.org/10.1016/j.sna.2015.09.018.

Kalita, J.M., Chithambo, M.L., 2017a. On the sensitivity of thermally and optically stimulated luminescence of $\alpha-\mathrm{Al} 2 \mathrm{O} 3: \mathrm{C}$ and $\alpha-\mathrm{Al} 2 \mathrm{O} 3: \mathrm{C}, \mathrm{Mg}$. Radiat. Meas. 99, 18-24. https://doi.org/10.1016/j.radmeas.2017.03.006.

Kalita, J.M., Chithambo, M.L., 2017b. Comprehensive kinetic analysis of thermoluminescence peaks of $\alpha$-Al2O3:C,Mg. J. Lumin. 185, 72-82. https://doi.org/10. 1016/j.jlumin.2017.01.003.

Kalkanci, H., Kurnaz, S.C., 2008. The effect of process parameters on mullite-based plasma electrolytic oxide coatings. Surf. Coating. Technol. 203, 15-22. https://doi. org/10.1016/j.surfcoat.2008.07.015.

Khan, R.H.U., Yerokhin, A., Li, X., Dong, H., Matthews, A., 2010. Surface characterisation of DC plasma electrolytic oxidation treated 6082 aluminium alloy: effect of current density and electrolyte concentration. Surf. Coating. Technol. 205, 1679-1688. https://doi.org/10.1016/j.surfcoat.2010.04.052.

Liang, J., Srinivasan, P.B., Blawert, C., Störmer, M., Dietzel, W., 2009. Electrochemical corrosion behaviour of plasma electrolytic oxidation coatings on AM50 magnesium alloy formed in silicate and phosphate based electrolytes. Electrochim. Acta 54, 3842-3850. https://doi.org/10.1016/j.electacta.2009.02.004.

Martínez-Martínez, R., Rickards, J., García-Hipólito, M., Trejo-Luna, R., MartínezSánchez, E., Álvarez-Fregoso, O., Ramos-Brito, F., Falcony, C., 2005. RBS characterization of $\mathrm{Al} 2 \mathrm{O} 3$ films doped with Ce and Mn. Nucl. Instrum. Methods Phys. Res. Sect. B Beam Interact. Mater. Atoms 241, 450-453. https://doi.org/10.1016/j.nimb. 2005.07.054.

Meriç, N., Sahiner, E., Polymeris, G.S., 2015. Thermally assisted OSL (TA-OSL) reproducibility in Al2O3: C and its implication on the corresponding thermoluminescence (TL) reproducibility. Radiat. Meas. 1-5. https://doi.org/10.1016/j. radmeas.2015.12.015.

Palan, C.B., Bajaj, N.S., Omanwar, S.K., 2016. Luminescence properties of terbium-doped Li3PO4 phosphor for radiation dosimetry. Bull. Mater. Sci. 39, 1619-1623. https:// doi.org/10.1007/s12034-016-1309-5.

Rodriguez, M.G., Denis, G., Akselrod, M.S., Underwood, T.H., Yukihara, E.G., 2011. Thermoluminescence, optically stimulated luminescence and radioluminescence properties of Al2O3:C,Mg. Radiat. Meas. 46, 1469-1473. https://doi.org/10.1016/j. radmeas.2011.04.026.

Salek, G., Devoti, A., Lataste, E., Demourgues, A., Garcia, A., Jubera, V., Gaudon, M., 2016. Optical properties versus temperature of $\mathrm{Cr}$-doped $\gamma$ - and $\alpha$-Al2O3: irreversible thermal sensors application. J. Lumin. 179, 189-196. https://doi.org/10.1016/j. jlumin.2016.07.004.

Smits, K., Millers, D., Zolotarjovs, A., Drunka, R., Vanks, M., 2015. Luminescence of Eu ion in alumina prepared by plasma electrolytic oxidation. Appl. Surf. Sci. 337, 166-171. https://doi.org/10.1016/j.apsusc.2015.02.085.

Snizhko, L.O., Yerokhin, A.L., Pilkington, A., Gurevina, N.L., Misnyankin, D.O., Leyland, A., Matthews, A., 2004. Anodic processes in plasma electrolytic oxidation of aluminium in alkaline solutions. Electrochim. Acta 49, 2085-2095. https://doi.org/10. 1016/j.electacta.2003.11.027.

Stojadinović, S., Tadić, N., Vasilić, R., 2016. Photoluminescence of Sm3+ doped ZrO2 coatings formed by plasma electrolytic oxidation of zirconium. Mater. Lett. 164 329-332. https://doi.org/10.1016/j.matlet.2015.11.056.

Tanir, G., Cengiz, F., Hicabi Bölükdemir, M., 2012. Measurement of dose given by Co-60 in radiotherapy with TLD-500, Radiat. Phys. Chem. 81, 355-357. https://doi.org/10. 1016/j.radphyschem.2011.12.001.

Tian, J., Luo, Z., Qi, S., Sun, X., 2002. Structure and antiwear behavior of micro-arc oxidized coatings on aluminum alloy. Surf. Coating. Technol. 154, 1-7. https://doi. org/10.1016/S0257-8972(01)01671-1.

White, L., Koo, Y., Neralla, S., Sankar, J., Yun, Y., 2016. Enhanced mechanical properties and increased corrosion resistance of a biodegradable magnesium alloy by plasma electrolytic oxidation (PEO). Mater. Sci. Eng. B 208, 39-46. https://doi.org/10.1016/ j.mseb.2016.02.005.

Xin, S., Song, L., Zhao, R., Hu, X., 2006. Influence of cathodic current on composition, structure and properties of Al2O3coatings on aluminum alloy prepared by micro-arc oxidation process. Thin Solid Films 515, 326-332. https://doi.org/10.1016/j.tsf. 2005.12.087.

Yang, X., Li, H., Cheng, Y., Tang, Q., Su, L., Xu, J., 2008. Growth of highly sensitive thermoluminescent crystal $\alpha$-Al2O3:C by the temperature gradient technique. J. Cryst. Growth 310, 3800-3803. https://doi.org/10.1016/j.jcrysgro.2008.05.047.

Yerokhin, A.L., Lyubimov, V.V., Ashitkov, R.V., 1998. Phase formation in ceramic 
coatings during plasma electrolytic oxidation of aluminium alloys. Ceram. Int. 24, 1-6. https://doi.org/10.1016/S0272-8842(96)00067-3.

Yerokhin, A.L., Nie, X., Leyland, A., Matthews, A., Dowey, S.J., 1999. Plasma electrolysis for surface engineering. Surf. Coating. Technol. 122, 73-93. https://doi.org/10. 1016/S0257-8972(99)00441-7.

Yerokhin, A.L., Snizhko, L.O., Gurevina, N.L., Leyland, A., Pilkington, A., Matthews, A., 2003. Discharge characterization in plasma. J. Phys. D Appl. Phys. 36, 2110-2120.
Yong, L.C., Wagiran, H., Ismail, A.K., 2013. Thermoluminescence performance of carbondoped aluminium oxide for dose measurement by various preparation methods. Sci. Eng. 3, 109-113.

Zolotarjovs, A., Smits, K., Krumina, A., Millers, D., Grigorjeva, L., 2016. Luminescent PEO coatings on aluminum. ECS J. Solid State Sci. Technol. 5, R150-R153. https://doi. org/10.1149/2.0401609jss.

Institute of Solid State Physics, University of Latvia as the Center of Excellence has received funding from the European Union's Horizon 2020 Framework Programme H2020-WIDESPREAD-01-2016-2017-TeamingPhase2 under grant agreement No. 739508, project CAMART² 